W. C. FU, T. F. JAMISON* (MASSACHUSETTS INSTITUTE OF TECHNOLOGY, CAMBRIDGE, USA)

Deuteriodifluoromethylation and gem-Difluoroalkenylation of Aldehydes Using $\mathrm{ClCF}_{2} \mathrm{H}$ in Continuous Flow

Angew. Chem. Int. Ed. 2020, DOI: 10.1002/anie.202004260.

\title{
Synthesis of Deuterodifluoromethylated Alcohols and gem-Difluoroalkenes in Continuous Flow
}

Preparation of deuterodifluoromethylated alcohols in continous flow:

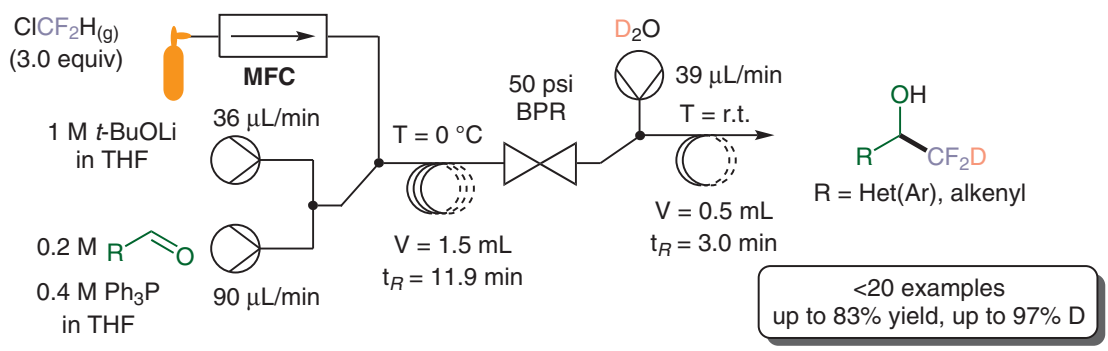

Preparation of $g e m$-difluoroalkenes in continous flow:

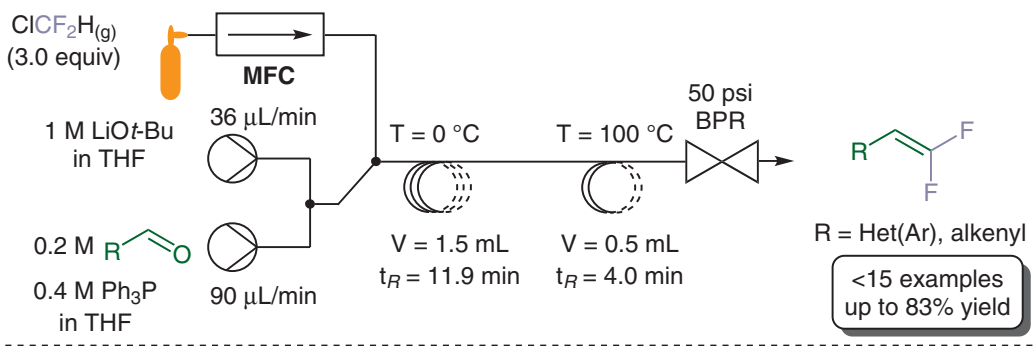

Selected examples:

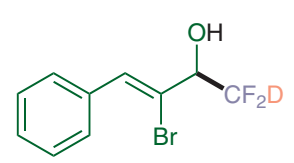

$59 \%$ yield, $95 \%$ D

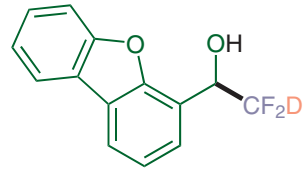

$71 \%$ yield, $97 \%$ D<smiles>FC(F)=Cc1ccc(F)c(Oc2ccccc2)c1</smiles>

$61 \%$ yield<smiles>CCCN(CCC)S(=O)(=O)c1ccc(/C=C/P)cc1</smiles>

Probenecid $74 \%$ yield
Significance: Fu and Jamison report the utilization of chlorodifluoromethane gas in a continuousflow setup for the preparation of $\alpha$-deuteriodifluoromethylated benzyl alcohols and gem-difluoroalkenes from a range of aldehydes in good yields.
Comment: Interestingly, the authors performed NMR studies that led them to propose a plausible reaction mechanism involving an oxaphosphetane intermediate. Furthermore, the authors demonstrated the utility of this method by performing various derivatizations of the $\alpha$-deuteriodifluoromethylated benzyl alcohol, affording the corresponding, bromide, tosylate or ketone. 